\title{
What Drives the Seasonal Onset and Decay of the Western Hemisphere Warm Pool?
}

\author{
S.-K. LEE \\ Cooperative Institute for Marine and Atmospheric Studies, University of Miami, Miami, Florida \\ D. B. ENFIELD AND C. WANG \\ NOAA/Atlantic Oceanographic and Meteorological Laboratory, Miami, Florida
}

(Manuscript received 23 March 2005, in final form 8 September 2006)

\begin{abstract}
The annual heat budget of the Western Hemisphere warm pool (WHWP) is explored using the output of an ocean general circulation model (OGCM) simulation. According to the analysis, the WHWP cannot be considered as a monolithic whole with a single set of dominating processes that explain its behavior. The three regions considered, namely the eastern north Pacific (ENP), the Gulf of Mexico (GoM), and the Caribbean Sea $(\mathrm{CBN})$, are each unique in terms of the atmospheric and oceanic processes that dominate the corresponding heat budgets. In the ENP region, clear-sky shortwave radiation flux is responsible for the growth of the warm pool in boreal spring, while increased cloud cover in boreal summer and associated reduction in solar radiation play a crucial role for the ENP warm pool's demise. Ocean upwelling in the Costa Rica Dome connected to surrounding areas by horizontal advection offers a persistent yearlong cooling mechanism. Over the Atlantic, the clear-sky radiation flux that increases monotonically from December to May and decreases later is largely responsible for the onset and decay of the Atlantic-side warm pool in boreal summer and fall. The CBN region is affected by upwelling and horizontal advective cooling within and away from the coastal upwelling zone off northern South America during the onset and peak phases, thus slowing down the warm pool's development, but no evidence was found that advective heat flux divergence is important in the GoM region. Turbulent mixing is also an important cooling mechanism in the annual cycle of the WHWP, and the vertical shear at the warm pool base helps to sustain the turbulent mixing. Common to all three WHWP regions is the reduction of wind speed at the peak phase, suggestive of a convection-evaporation feedback known to be important in the Indo-Pacific warm pool dynamics.
\end{abstract}

\section{Introduction}

The Western Hemisphere Warm Pool (WHWP) is a warm body of surface water that appears between March and October in the Western Hemisphere over the eastern north Pacific (ENP), the Gulf of Mexico (GoM), and the Caribbean Sea (CBN; Wang and Enfield 2001). During its warming (onset) phase, the WHWP responds to atmospheric heat fluxes across the air-sea interface, expanding its warm pool boundary. Once it is fully charged, the WHWP releases large amounts of moisture into the overlying atmosphere, thus affecting the deep tropical convection in the West-

Corresponding author address: Sang-Ki Lee, Cooperative Institute for Marine and Atmospheric Studies, University of Miami, 4600 Rickenbacker Causeway, Miami, FL 33149.

E-mail: sang-ki.lee@noaa.gov ern Hemisphere (Wang and Enfield 2003), and the rainfall over the continental United States and Central America (Bosilovich 2002; Wang et al. 2006).

In our previous observational work, Enfield and Lee (2005, hereafter EL05) showed that the seasonal warming of the WHWP is largely forced by the shortwave radiation cycle (with modification by cloud cover in the ENP), while the latent heat flux plays a secondary but important role particularly during the cooling (decay) phase. EL05 also showed that the diffusive heat exchange with the cooler surroundings is the major damping mechanism of the warm pool, with its rate in the range between $-23.6(\mathrm{ENP})$ and $-9.3 \mathrm{~W} \mathrm{~m}^{-2}(\mathrm{CBN})$, and that the advective heat flux divergence plays a relatively minor role in the ENP and GoM regions, with its rate between $-5.5(\mathrm{GoM})$ and $-2.0 \mathrm{~W} \mathrm{~m}^{-2}$ (ENP). The diffusive heat flux and oceanic advective heat flux divergence obtained in EL05 are subject to large errors

DOI: $10.1175 / J C L I 4113.1$

(C) 2007 American Meteorological Society 


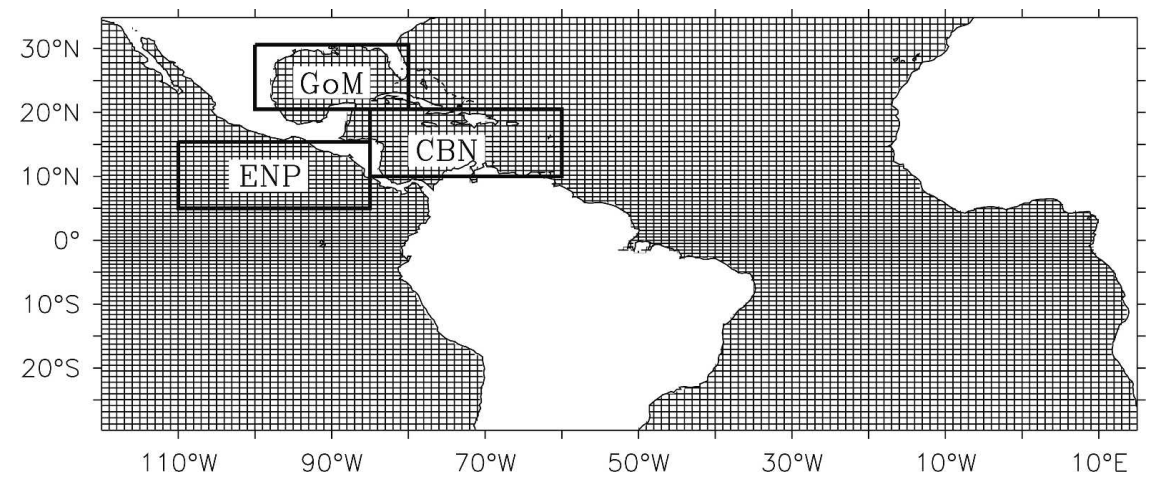

FIG. 1. The model grid structure in the eastern tropical Pacific and the tropical Atlantic analysis domain (uniform $1^{\circ}$ in zonal and variable in meridional direction; $0.5^{\circ}$ at the equator increasing linearly to $1^{\circ}$ at $40^{\circ}$ latitude and $1^{\circ}$ poleward of $40^{\circ}$ ). The locations of the three subregions of the WHWP are also shown. Note that the entire model domain contains both Pacific and Atlantic Oceans between $100^{\circ}$ and $20^{\circ} \mathrm{E}$, bounded north and south by $35^{\circ} \mathrm{S}$ and $65^{\circ} \mathrm{N}$, respectively.

due to the bias in surface heat flux data and the sparseness of surface drifter data. Nevertheless, their findings are consistent with Niiler and Stevenson's (1982) conclusion that turbulent mixing is the only mechanism that damps out the net heat gain at the sea surface because the water that enters a warm pool has the same temperature as the water that leaves it. Unlike the Indo-Pacific warm pool, which is large year-round, the WHWP is highly time dependent as it appears only for four months in the ENP and shifts to the GoM and then to the CBN and lasts there only for another four months. Since the warm pool thermodynamics envisioned by Niiler and Stevenson (1982) is valid strictly for the steady-state condition, the heat budget of the WHWP is less likely to be dictated by the isothermal condition at the warm pool boundary, which is expanding and contracting seasonally in response to the imbalance between warming and cooling processes. This leads us to suspect that the advective heat flux divergence may be important in the WHWP cycle, at least in certain geographic regions.

To surmount the shortcoming of EL05 and to better assess the dominant forcing and damping mechanisms that operate in the WHWP, we explore the annual heat budget cycle of the WHWP using the output from the fine-tuned Hybrid Coordinate Ocean Model (HYCOM) simulation of Lee et al. (2005, henceforth LEW05), with particular emphasis on the impact of ocean dynamics. To properly assess the impact of ocean dynamics, we use a $27.5^{\circ} \mathrm{C}$ isotherm and mixed layer depth to locate approximate positions and boundaries of the warm pool, and then the heat conservation equation is vertically integrated to derive a so-called slab heat budget equation, which is in turn applied to the 12 monthly outputs from the HYCOM simulation. In the following sections, after briefly describing the HYCOM simulation (section 2), the slab heat budget equation is derived (section 3) and the dominant atmosphere-ocean processes responsible for the forcing and damping of three WHWP regions are discussed, based on the slab heat budget analysis (section 4). Temporal and spatial variations in the mixed layer depth and their potential impact on the WHWP heat budget cycle are assessed and discussed in section 5. In section 6, the modelgenerated values of diffusive and advective heat flux are compared with those of EL05, and a summary and discussion is provided in section 7 .

\section{HYCOM simulation}

The details on the HYCOM simulation are documented in LEW05, thus they are summarized only briefly here. The model domain contains both the Pacific and Atlantic Oceans between $100^{\circ}$ and $20^{\circ} \mathrm{E}$, bounded north and south by $65^{\circ} \mathrm{N}$ and $35^{\circ} \mathrm{S}$, respectively. The grid resolution is uniform $1^{\circ}$ zonally and variable in the meridional direction; $0.5^{\circ}$ at the equator increasing linearly to $1^{\circ}$ at $40^{\circ}$ latitude and remaining $1^{\circ}$ poleward of $40^{\circ}$. The grid structure in the eastern tropical Pacific and the tropical Atlantic, and the locations of the three regions of the WHWP, are indicated in Fig. 1. The constrained Southampton surface flux climatology (SHC; Grist and Josey 2003) is used to force HYCOM since it is the least biased over the WHWP regions among the eight surface flux climatologies considered in LEW05. The optimal nature of the SHC is consistent with the observational results of EL05 and the result from a direct comparison with mooring data at the Eastern Pacific Investigation of Climate Studies (EPIC) and Pilate Research Moored Array in the 
Tropical Atlantic (PIRATA) sites (EL05). See LEW05 for more discussion about HYCOM's sensitivities to other surface flux data.

HYCOM mainly uses the potential density as the vertical coordinate, but it allows the vertical coordinate to become pressure-like ( $z$ coordinate) near the ocean surface and uses the sigma coordinate (terrainfollowing) in shallow water regions. The major advantage of using such a complex vertical coordinate system is to provide appropriate vertical resolution in the surface mixed layer and shallow water area. However, one trade-off is that HYCOM uses the so-called hybrid grid generator, which is a numerical scheme that reconstructs the layer structure during the model integration to match the predefined target density of each layer (Bleck 2002). The hybrid grid generator acts like an "upstream" vertical advection operator, which is known to be diffusive (Bleck 2002). Numerical diffusion of such nature can have serious consequences in the heat tendency of the nonisopycnal layers. Therefore, an antidiffusion scheme is introduced in the latest HYCOM release (version 2.1) to reduce the numerical diffusion. In this study, however, instead of applying the antidiffusion scheme, we simply finesse the problem by forcing the surface five nonisopycnal layers to have prefixed uniform thickness (each of $10 \mathrm{~m}$ ) throughout the model integration. In this way, the hybrid grid generator does not cause numerical diffusion in the upper $50 \mathrm{~m}$. Below the 5 uniform thickness layers, 17 nonuniform hybrid layers are used (total 22 layers). The target densities for the 17 deeper layers are 23.25, 24.00, 24.70, $25.28,25.77,26.18,26.52,26.80,27.03,27.22,27.38$, $27.52,27.64,27.74,27.82,27.88$, and 27.94 in the $\sigma_{\theta}$ unit, as optimized for the North Atlantic Ocean. The model is initialized with the January Levitus climatology (Levitus and Boyer 1994; Levitus et al. 1994), and temperature, salinity, and layer thickness fields at the five grid latitudes adjacent to the northern and southern boundaries are relaxed back to the monthly Levitus climatology with a damping time of approximately 3 months. The sea surface salinity (SSS) is updated by fully incorporating the precipitation data from the Southampton climatology (Grist and Josey 2003). However, since the salinity is not the major focus in this study, the SSS (but not the SST) is relaxed back to the Levitus climatology with the $e$-folding time of 30 days. The $K$-profile parameterization (KPP) scheme of Large et al. (1994) is used to parameterize the vertical turbulent mixing. The time- and space-dependent light attenuation depth is derived from space-based ocean color measurements to simulate penetrative shortwave heat flux. The WHWP SST bias in the fine-tuned case ranges between $-0.36^{\circ}$ and $0.25^{\circ} \mathrm{C}$ (LEW05).

\section{Slab heat budget equation}

We use a slab heat budget analysis as the major tool for exploring the annual heat budget cycle of the WHWP. As shown in Fig. 1, the sea surface and the fixed side and bottom boundaries bound the three regional warm pool slabs. A critical issue is how to determine the depth of these warm pool slabs. To have physical significance, here we choose the depth of a warm pool slab to be as close as the area-averaged mixed layer depth during the peak months of the warm pool. Thus, the mixed layer depth averaged over the ENP region (Fig. 1) during the peak months of April to June is approximately $20 \mathrm{~m}$ according to the World Ocean Atlas (WOA) climatology (Conkright et al. 2002). Similarly, the slab depth for GoM and CBN regions are chosen to be 20 and $40 \mathrm{~m}$, respectively. (See Table 2 in EL05 for more detail.)

Integration of the heat conservation equation from the sea surface to slab bottom yields

$$
\underbrace{\frac{d}{d t} \int_{-d}^{0} \rho c_{p} T d z}_{Q_{\mathrm{STR}}}=\underbrace{\left.R\right|_{0}+Q_{\mathrm{LAT}}+Q_{\mathrm{SEN}}}_{Q_{\mathrm{NET}}} \underbrace{-\left.R\right|_{z=-d}}_{Q_{\mathrm{SWP}}} \underbrace{\int_{-d}^{0} \rho c_{p}\left(\mathbf{v} \cdot \boldsymbol{\nabla} T+w \frac{\partial T}{\partial z}\right) d z}_{Q_{\mathrm{ADV}}}+\underbrace{\left.\overline{w^{\prime} T^{\prime}}\right|_{-d}}_{Q_{\mathrm{DIF}}}
$$

where $\rho$ is the water density, $c_{p}$ is the specific heat of seawater, $\mathbf{v}$ is the horizontal velocity vector, $R$ is the radiative heat flux at a given depth, and $d$ is the depth of slab. The lhs is the heat storage rate $\left(Q_{\text {STR }}\right)$, and the rhs includes the surface net heat flux $\left(Q_{\mathrm{NET}}\right)$, the penetrative shortwave heat flux at the slab base $\left(Q_{\text {SwP }}\right)$, the horizontal and vertical advective heat flux divergence $\left(Q_{\mathrm{ADV}}\right)$, and the vertical diffusive heat flux across the slab base $\left(Q_{\mathrm{DIF}}\right)$, respectively. Note that the horizontal subgrid diffusion term, although it is a part of the model heat equation, is not included in (1) because it is usually very small. For convenience, the turbulent heat flux term $\left(Q_{\text {DIF }}\right)$ also contains heating associated with winter convection.

The surface net heat flux $\left(Q_{\mathrm{NET}}\right)$ can be written as

$$
Q_{\mathrm{NET}}=Q_{\mathrm{SWR}}+Q_{\mathrm{LWR}}+Q_{\mathrm{LAT}}+Q_{\mathrm{SEN}} \text {, }
$$

where $Q_{\mathrm{SWR}}, Q_{\mathrm{LWR}}, Q_{\mathrm{LAT}}$, and $Q_{\mathrm{SEN}}$ represent shortwave radiative flux, longwave radiative flux, latent heat flux, and sensible heat flux, respectively. The conven- 
tion in this paper is that the positive heat flux means heat gain for the ocean and the negative means heat loss. The shortwave radiative heat flux at the sea surface can be expressed further as the sum of the clearsky radiative heat flux $\left(Q_{\mathrm{CSR}}\right)$ and cloud radiative forcing $\left(Q_{\mathrm{CRF}}\right)$ components:

$$
Q_{\mathrm{SWR}}=Q_{\mathrm{CSR}}+Q_{\mathrm{CRF}}
$$

Note that the cloud radiative forcing is difficult to measure. Therefore, we first obtain the clear-sky radiative heat flux data from the National Centers for Environmental Prediction-National Center for Atmospheric Research (NCEP-NCAR) global reanalysis 1 (NCEP1; Kalnay et al. 1996), then $Q_{\mathrm{CRF}}$ is computed by subtracting the NCEP1 clear-sky radiative heat flux from the total shortwave heat flux of SHC data (Grist and Josey 2003). The latent heat flux can be also divided into components:

$$
Q_{\mathrm{LAT}}=\bar{Q}_{\mathrm{LAT}}+Q_{\mathrm{LAT}_{T}}+Q_{\mathrm{LAT}_{W}}+Q_{\mathrm{LAT}_{S}}
$$

where the first term in the rhs is the annual mean, and the other three terms represent the SST-humidityinduced $\left(Q_{\mathrm{LAT}_{T}}\right)$, wind speed-induced $\left(Q_{\mathrm{LAT}_{W}}\right)$, and synoptic $\left(Q_{\mathrm{LAT}_{S}}\right)$ latent heat flux components, respectively. These may be written as

$$
\begin{aligned}
Q_{\mathrm{LAT}_{T}} & =\rho L C_{E}|\bar{U}|\left(q_{a}^{\prime}-q_{s}^{\prime}\right), \\
Q_{\mathrm{LAT}_{W}} & =\rho L C_{E}\left|U^{\prime}\right|\left(\bar{q}_{a}-\bar{q}_{s}\right), \\
Q_{\mathrm{LAT}_{S}} & =\rho L C_{E}\left|U^{\prime}\right|\left(q_{a}^{\prime}-q_{s}^{\prime}\right),
\end{aligned}
$$

where the variables with overbars indicate the annual mean and the variables with primes indicate the perturbation from the annual mean, $L$ is the latent heat of evaporation $\left[2.47 \times 10^{6} \mathrm{~J}(\mathrm{~kg})^{-1}\right], C_{E}$ is the transfer coefficient for latent heat (0.00143), $U$ is the wind speed at $z=10 \mathrm{~m}, q_{a}$ is specific humidity at $z=10 \mathrm{~m}$, and $q_{S}$ is the saturation specific humidity at the sea surface temperature.

In the following section, the heat flux equations derived here are used to describe the annual heat budget cycle of the WHWP. The heat flux terms in (1)-(7) are obtained by first computing them at each time step during the model integration and then taking the monthly averages for $5 \mathrm{yr}$ between the model years 11 and 15 . The advective heat flux divergence term $\left(Q_{\mathrm{ADV}}\right)$, thus, contains both mean and eddy contributions.

\section{Annual heat budget cycle of the WHWP}

\section{a. Eastern North Pacific}

The top panel in Fig. 2 shows the observed versus simulated seasonal cycle of the volume-averaged tem-

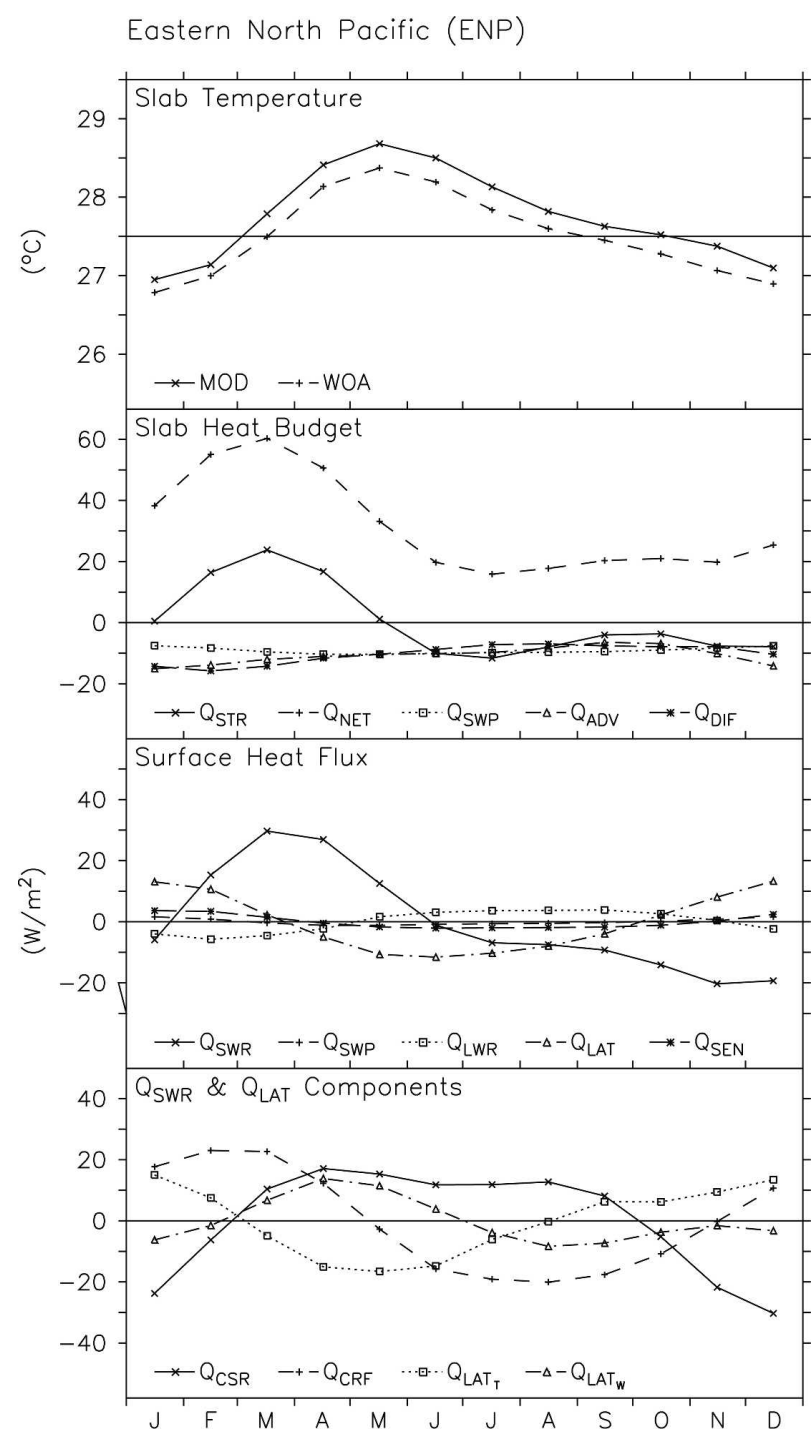

FIG. 2. The seasonal cycle of the area-averaged thermal flux properties in the ENP slab. (top) The temperature and (second and third from top) the slab heat budget and surface heat flux, respectively. (bottom) The shortwave radiative heat flux and latent heat flux components. (bottom two panels) The annual mean components $\left(\bar{Q}_{\mathrm{SWR}}=203.6, \bar{Q}_{\mathrm{SWP}}=-9.2, \bar{Q}_{\mathrm{LWR}}=-50.6, \bar{Q}_{\mathrm{LAT}}\right.$ $=-113.4, \bar{Q}_{\mathrm{SEN}}=-8.1, \bar{Q}_{\mathrm{CSR}}=281.1$, and $\left.\bar{Q}_{\mathrm{CRF}}=-77.7\right)$ are removed for easier comparison.

perature for the ENP slab. The observed slab temperature is obtained from the WOA climatology (Conkright et al. 2002). The depth of slab is taken as $20 \mathrm{~m}$, which is approximately the mixed layer depth averaged over the ENP region during the peak months of April to June. The seasonal cycle of the slab temperature is quite regular, increasing from January to April, and decreasing in other months. The simulated slab temperature is positively biased, with the annual mean offset of about $0.24^{\circ} \mathrm{C}$. For future reference, the three months prior to 
the peak month are hereafter referred to as the onset phase [February-April (FMA, herafter 3-month periods are denoted by the first letter of each respective month)], the three months centered at the peak month as the peak phase (AMJ), and the three months after the peak month as the decay phase (JJA).

The simulated slab heat budget cycle (area-averaged) shown in the second panel indicates that, during the onset phase, the net surface heat flux $\left(Q_{\mathrm{NET}}+Q_{\mathrm{SWP}}=\right.$ $45.9 \mathrm{~W} \mathrm{~m}^{-2}$ ) forces the warming of the ENP slab while the diffusive heat flux $\left(-13.9 \mathrm{~W} \mathrm{~m}^{-2}\right)$ and advective flux divergence $\left(-12.3 \mathrm{~W} \mathrm{~m}^{-2}\right)$ damp out the heat. The decay phase starts after the peak in May and the rapid reduction of the surface net heat flux $\left(Q_{\mathrm{NET}}+Q_{\mathrm{SWP}}=\right.$ $8.0 \mathrm{~W} \mathrm{~m}^{-2}$ ) helps the ENP to cool off. The diffusive $\left(-7.6 \mathrm{~W} \mathrm{~m}^{-2}\right)$ and advective cooling $\left(-9.4 \mathrm{~W} \mathrm{~m}^{-2}\right)$ is slightly less intense in the decay phase. The horizontal component of the advective heat flux divergence is a cooling term during the onset phase $\left(-2.9 \mathrm{~W} \mathrm{~m}^{-2}\right)$, but it is negligible compared to the vertical component during the peak phase $\left(0.7 \mathrm{~W} \mathrm{~m}^{-2}\right)$. The penetrative shortwave radiation is quite large throughout the year, with the annual mean of about $-9.2 \mathrm{~W} \mathrm{~m}^{-2}$, because the ENP warm pool is relatively shallow.

The third panel shows the surface heat flux components, and the fourth panel shows the components for the shortwave radiation and the latent heat flux. For easier comparison among the terms, the annual mean components are removed and only the deviations from the annual mean are shown in the two panels. The monthly variations of the sensible heat and the longwave radiation are relatively small in comparison to the shortwave radiation and latent heat flux variations. Clearly, the rapid increase in net surface flux from December to March is due to the intensifying shortwave radiation. As noted in EL05, the cloud radiative forcing then decreases very rapidly from the onset to the decay phase, standing out as the major factor in reducing the net surface flux and allowing the warm pool to cool off. Note that the clear-sky radiative heat flux remains strong until September. But, the increased cloudiness associated with the Pacific ITCZ approaching from the south, and the onset of the monsoon from the southwest blocks much of the shortwave radiation during the decay phase, indicating that the shielding effect of deep convective clouds is a critical factor in cooling off the ENP as hypothesized by Ramanathan et al. (1995) for the Indo-Pacific warm pool.

The SST-humidity-induced latent heat flux largely follows the slab temperature cycle, thus yielding maximum cooling during the peak months of the ENP slab. The wind speed-induced evaporative cooling over ENP is weaker during the onset and peak phases but stron- ger during the summer decay phase when the low-level easterly flow is stronger. The total latent heat flux, therefore, increases in the peak and decay phases, providing the moisture seed to the atmosphere aloft needed for the deep tropical convection in boreal summer, at the same time as it helps to cool the ENP warm pool. An interesting point is that the reduction of wind speed during the peak phase fits the description of the convection-evaporation negative feedback (CE feedback hereafter) known to be important in the IndoPacific warm pool dynamics (Zhang et al. 1995). The CE feedback argues that, once the tropical Pacific water is sufficiently warmed, surface wind is weakened because of large-scale low-level airmass convergence accompanied by deep tropical convection. The CE feedback is supported by statistical evidence that evaporation tends to decrease (or at least does not increase) after reaching peak SST of $28^{\circ} \mathrm{C}$ over the tropical Pacific (Zhang and McPhaden 1995).

One of our main goals is to better understand the role of the ocean in the annual cycle of the WHWP. Figure 3 (top) clearly shows that the vertical advective heat flux divergence (colored), which is particularly intense during the onset phase, is forced by the positive wind stress curl (contoured lines) associated with the winter-time mountain pass jets that appear in the Gulfs of Tehuantepac and Papagayo (McCreary et al. 1989; Chelton et al. 2000). The positive wind stress curl remains strong during the peak and decay phases because of the southwest monsoon onset. Eventually, the vertical advective cooling in the region is responsible for the spawning of the Costa Rica Dome in boreal summer (Hofmann et al. 1981). Xie et al. (2005) reported that the reduced SST over the Costa Rica Dome creates a hole with about $500 \mathrm{~km}$ in diameter in the convective cloud system, thus reducing the local precipitation by half that of the surrounding region in boreal summer.

Figure 3 (bottom) shows the rate of horizontal advective heat flux divergence above the slab base at $20 \mathrm{~m}$ (colored) and the velocity vector averaged vertically for the upper $20 \mathrm{~m}$. It clearly shows that the cold upwelled water is advected northwestward into the Gulfs of Tehuantepac and Papagayo, but due to the advection of warm water from the equatorial Pacific, the areaaveraged rate of horizontal advective heat flux divergence is relatively small in the ENP slab. Although not shown here, we find that the region of large turbulent heat flux corresponds to the region of increased vertical shear, suggesting that the ENP may be prone to shear instability. This result supports the microstructure observation of the upper ocean conducted near $10^{\circ} \mathrm{N}$, $95^{\circ} \mathrm{W}$ during the EPIC2001 field program (Raymond et al. 2004). 


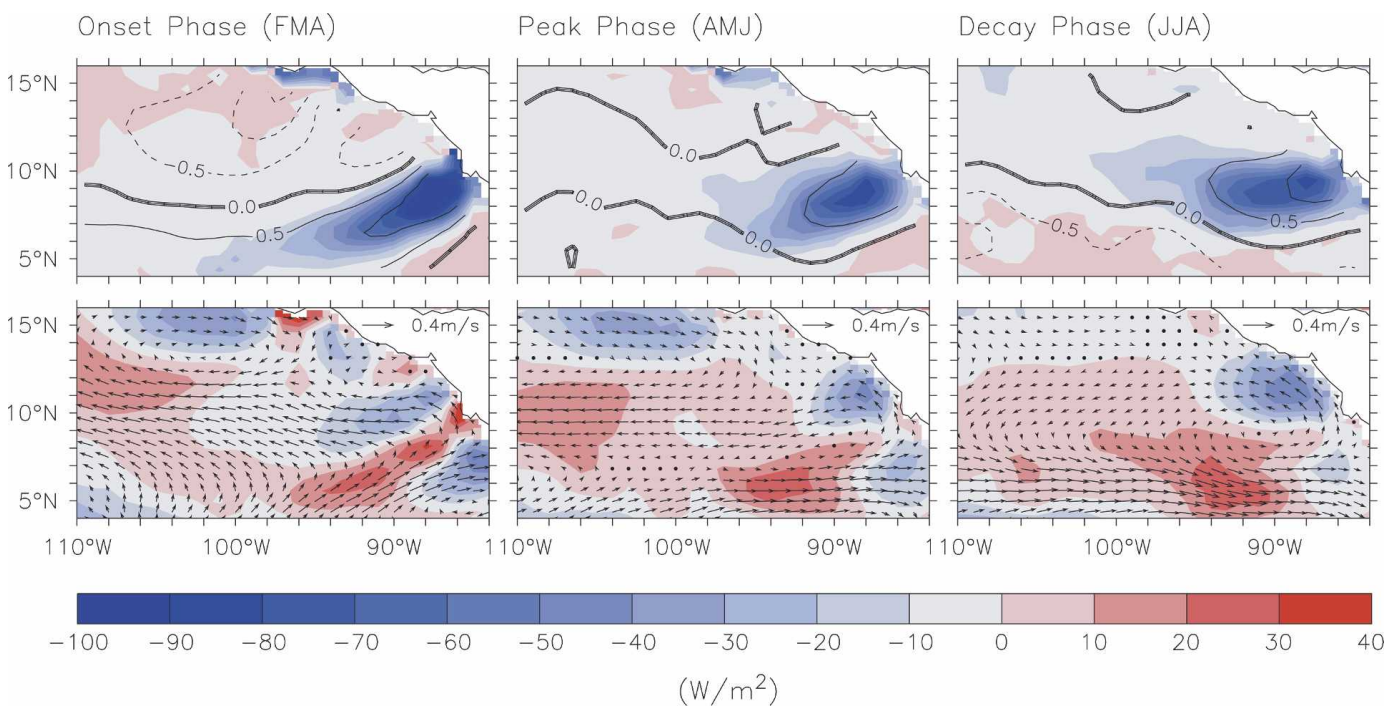

FIG. 3. (top) The vertical advective heat flux divergence rate (colored) and wind stress curl $\left(10^{7} \mathrm{Nm}^{-3}\right.$; contoured) for the ENP slab. (bottom) The rate of horizontal advective heat flux divergence $\left(\mathrm{W} \mathrm{m}^{-2}\right)$ above the slab base (colored) and the velocity vector averaged vertically for the upper $20 \mathrm{~m}$. (left) The onset phase (FMA), (middle) the peak phase (AMJ), and (right) the decay (JJA) phase.

In summary, the ENP warm pool develops in the spring primarily in response to increasing solar radiation, aided by reduced evaporation. As the warm pool size and intensity peak in April-June and the Central and North American landmasses warm, the southwest monsoon over the Panama Bight and the Mexican Monsoon get their start, and cloud cover increases greatly for the remainder of the solar forcing season, ending in August. The reduced shortwave radiation at the surface, aided by increased evaporation, causes the warm pool to decay until the early months of the following year. Thus, the ENP portion of the warm pool aids in its own demise. Vertical advective (Ekmaninduced) and diffusive (shear-induced) processes are also important since they offer a persistent yearlong cooling mechanism.

\section{b. Gulf of Mexico}

Figure 4 is the same as Fig. 2, except for the GoM slab. The depth of the GoM slab is chosen to be $20 \mathrm{~m}$ following EL05. The GoM slab undergoes warming during March to July and cooling in other months. The simulated slab temperature is positively biased, with an annual mean offset of about $0.58^{\circ} \mathrm{C}$. During the winter months, the GoM experiences an intense cooling at the surface due to frequent midlatitude frontal passages and an associated increase in latent heat flux, resulting in a convective adjustment that overturns cooler surface water with warmer water below. The convective warming of the cold surface water explains the positive diffusive heat flux during the winter months. However, this convective warming is an artifact of not considering the much-deepened winter mixed layer. Once the intense turbulent mixing that occurs at the base of the deep winter mixed layer is considered, the net diffusive heat flux across the mixed layer base is a cooling term in winter (see section 5). The upshot is that our slab heat budget analysis is not valid for estimating the oceanic heat budget terms $\left(Q_{\mathrm{STR}}, Q_{\mathrm{SWP}}, Q_{\mathrm{ADV}}\right.$, and $\left.Q_{\mathrm{DIF}}\right)$ in the winter mixed layer heat budget; thus here we limit our discussions on these terms to nonwinter seasons.

As in the case of the ENP slab, the shortwave radiation and the latent heat flux are the major forcing terms in the GoM slab. However, the cloud radiative forcing is nearly constant throughout the year, leaving the clear-sky radiation as the largest forcing mechanism for the GoM slab, aided by the secondary forcing of latent heat flux. The SST-humidity-induced latent heat flux largely follows the slab temperature cycle with a phase lag of about one month, thus peaking around September. However, the wind speed-induced latent flux is minimized in the warm pool's peak months (JAS), possibly as a result of the CE feedback, canceling the large SST-humidity-induced latent heat flux. The total latent heat flux, therefore, increases rather slowly from the onset (MJJ) to the decay (SON) phase. The advective heat flux divergence seems to be insignificant over the year and cools the GoM slightly during the onset $(-1.7$ $\left.\mathrm{W} \mathrm{m}{ }^{-2}\right)$ and peak $\left(-7.1 \mathrm{~W} \mathrm{~m}^{-2}\right)$ months, in agreement 
Gulf of Mexico (GoM)

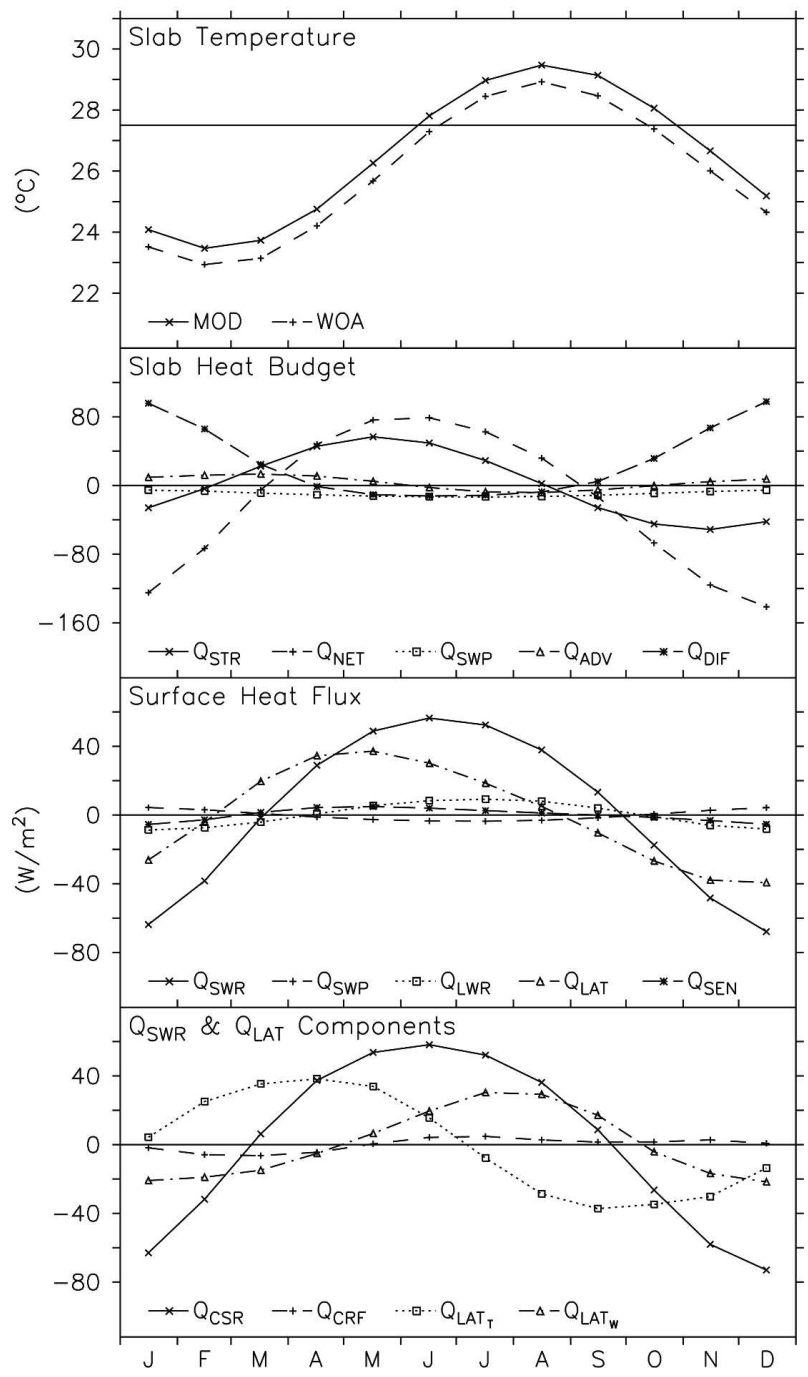

FIG. 4. Same as in Fig. 2, but for the GoM slab. (bottom two panels) The annual mean components $\left(\bar{Q}_{\mathrm{SWR}}=202.1, \bar{Q}_{\mathrm{SWP}}=\right.$ $-9.8, \bar{Q}_{\mathrm{LWR}}=-58.2, \bar{Q}_{\mathrm{LAT}}=-150.3, \bar{Q}_{\mathrm{SEN}}=-13.7, \bar{Q}_{\mathrm{CSR}}=$ 261.8 , and $\bar{Q}_{\mathrm{CRF}}=-63.4$ ) are removed for easier comparison.

with the slab-integrated residual calculated by EL05 from observations. However, it is important to note that the current model has a limited ability in resolving the regional western boundary current system (i.e., Yucatan Current, Loop Current, and Florida Current), which may have a significant impact on the heat budget cycle of the GoM slab. A high-resolution model simulation is needed to have a detailed and reliable assessment of the impact of ocean dynamics on the GoM warm pool. We also find that our slab heat budget analysis is not a valid tool for assessing the winter mixed layer heat budget over the GoM region. We further discuss the potential impact of the deepened winter mixed layer in section 5 .

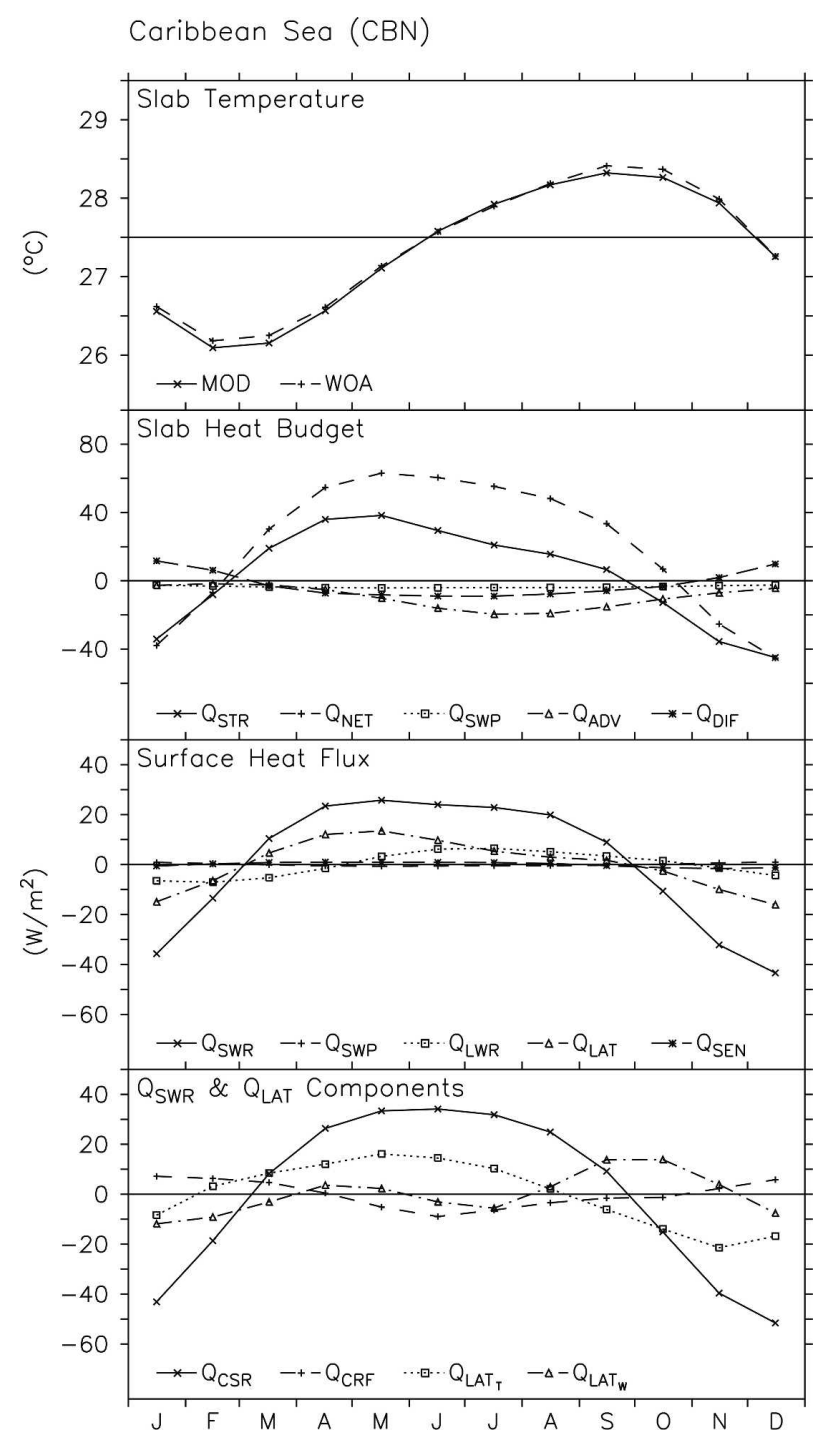

FIG. 5. Same as in Fig. 2, but for the CBN slab. (bottom two panels) The annual mean components $\left(\bar{Q}_{\text {SWR }}=214.2\right.$, $\bar{Q}_{\mathrm{SWP}}=-3.5, \bar{Q}_{\mathrm{LWR}}=-52.9, \bar{Q}_{\mathrm{LAT}}=-135.1, \bar{Q}_{\mathrm{SEN}}=-6.6$, $\bar{Q}_{\mathrm{CSR}}=274.8$, and $\bar{Q}_{\mathrm{CRF}}=-62.5$ ) are removed for easier comparison.

\section{c. Caribbean Sea}

In spite of shallow warm pool depths along the northern coast of South America, caused by coastal upwelling, a very deep region south of Cuba results in significantly greater $27.5^{\circ} \mathrm{C}$ isotherm depths, overall, than in the other regions (EL05). Here, the depth of the CBN slab is taken as $40 \mathrm{~m}$, which is approximately the regionally averaged mixed layer depth during the peak phase of the CBN warm pool (EL05). As shown in Fig. 5, the warming of the CBN slab starts in early March, as in the GoM slab, but continues into mid-September. The heat storage rate is much larger in the earlier stage of the warming (April and May) and weaker afterward 


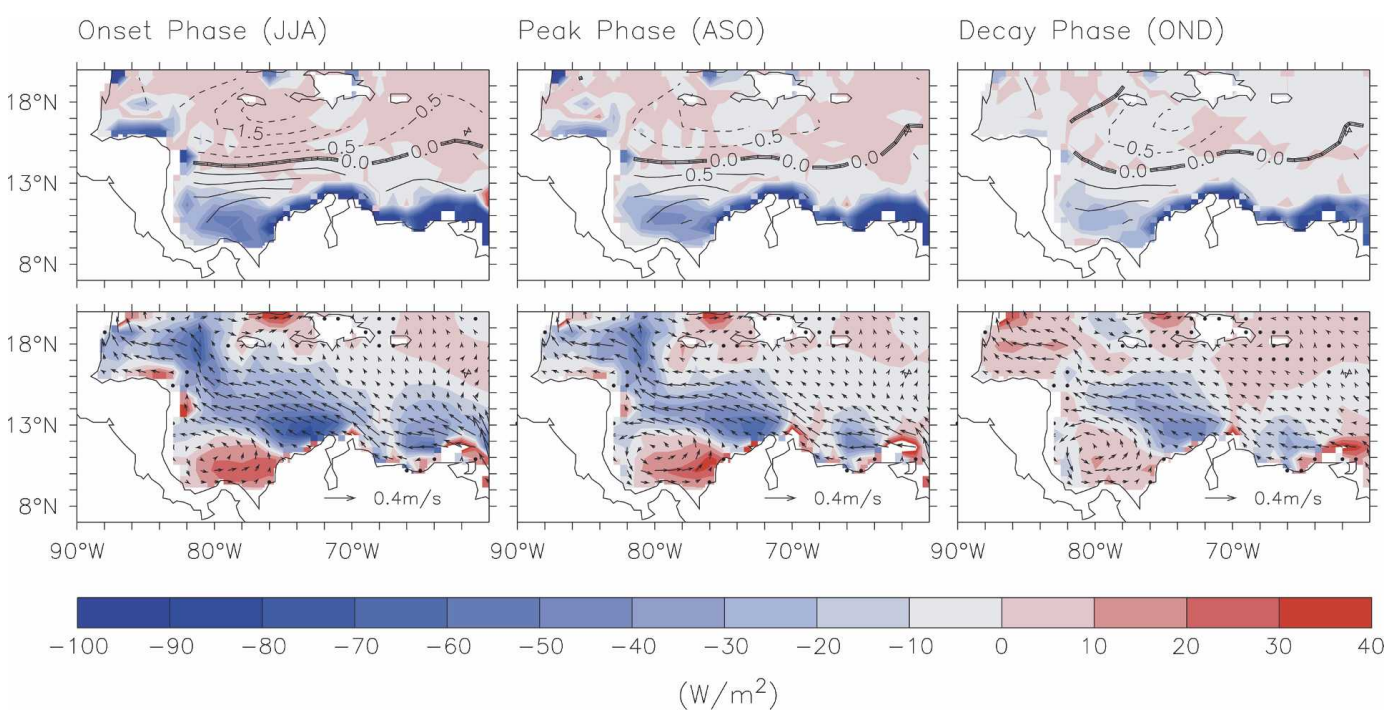

FIG. 6. (top) The vertical advective heat flux divergence rate (colored) and wind stress curl $\left(10^{7} \mathrm{Nm}^{-3}\right.$; contoured) for the CBN slab. (bottom) The rate of horizontal advective heat flux $\left(\mathrm{W} \mathrm{m}^{-2}\right)$ divergence above the slab base at $40 \mathrm{~m}$ (colored) and the velocity vector averaged vertically for the upper $40 \mathrm{~m}$. (left) The onset phase (JJA), (middle) the peak phase (ASO), and (right) the decay (OND) phase.

(JJAS). The advective heat flux divergence is insignificant between March and April, but it becomes the major cooling source between June and September $\left(-17.5 \mathrm{~W} \mathrm{~m}^{-2}\right)$, contributing to the significant reduction in the heat storage rate during the period of otherwise maximum development. The net effect is the reduced rate of increase in the slab temperature between June and September, as shown in the top panel. The diffusive cooling rate is smaller and does not vary much throughout the warming months between April and August, ranging between -7.2 and $-9.0 \mathrm{~W} \mathrm{~m}^{-2}$. During the winter, the decay of the CBN warm pool is primarily due to the sharp decrease in surface solar radiation. The positive diffusive heat flux during the winter is associated with wintertime convection, but it is an artifact of not considering the much-deepened winter mixed layer as discussed earlier. It will be shown in the next section that turbulent mixing across the deep winter mixed layer is indeed negative and it contributes to the demise of the CBN warm pool.

As in the ENP and GoM slabs, the monthly variations of the shortwave radiation and latent heat flux dominate the surface heat flux cycle. However, the shortwave radiation does not show much variation between April and August, while the latent heat flux is minimized between April and June, leading to slightly larger net surface heat flux in the earlier stage of the warming months (AMJ). The clear-sky radiation appears to be the major forcing mechanism for warming and cooling of the CBN slab. The cloud radiative forcing increases slightly between May and July, but it does not contribute much to the slab heat budget. The SSThumidity-induced latent heat flux roughly follows the slab temperature pattern with a phase lag of about 2 months, showing its peak in November. But the windinduced latent heat flux is minimized during the peak phase, possibly due to the CE feedback, and thus the total latent heat flux remains quite constant from July until mid-October. During the decay phase (OND), the wind-induced latent heat flux increases rapidly, while the SST-humidity-induced latent heat flux remains strong. The total latent heat flux, therefore, increases during the decay phase.

Figure 6 is the same as Fig. 3, except for the CBN. As shown in the upper panels, predominant easterlies and positive wind curl in the southern Caribbean are mainly responsible for the coastal upwelling off the South American continent. The cold upwelled water is then carried northwestward via the Caribbean Current, cooling the northwestern portion of the Caribbean Sea (lower panels). This spreading of the cold upwelled water is the critical factor that inhibits the development of the warm pool over the $\mathrm{CBN}$ region during the onset and peak phases. Further study using available observational data is required to confirm this finding. Although not shown here, the increased vertical shear along the path of the Caribbean Current is closely tied with the large turbulent heat flux measured at the slab base $(40 \mathrm{~m})$, suggesting that vertical shear is an important contributor to the turbulent mixing in the CBN warm pool.

One thing that distinguishes the $\mathrm{CBN}$ from the other 
warm pool regions is its large depth, which is due to isotherm depths south of Cuba that approach $100 \mathrm{~m}$. Over the deep portion of the CBN south of Cuba, weak to negative net heat flux at the sea surface due to occasional penetration of cold spells from the North American continent, combined with deep penetration of shortwave radiation, provides a favorable condition for a shallow convection to occur (McGregor and Nieuwolt 1998). The positive diffusive heat flux over the same area during the decay phase seems to support this explanation (not shown). Schneider et al. (1996) used a similar argument to explain why the western Pacific and Indonesian portion of the Indo-Pacific warm pool is deeper than the warm pool portion in the Indian Ocean. Another important factor that may influence the large warm pool depth south of Cuba is the Ekman convergence due to the negative wind stress curl on the northern side of the mean Caribbean low-level jet, which is persistent in all three phases of the CBN warm pool development. The core of the jet roughly coincides with the zero wind stress curl line as shown in Fig. 6. The relative importance of Ekman convergence versus negative surface heat flux in shaping the deep warm pool depth south of Cuba is not clear. We feel that this subject merits a separate analysis, and thus it is not pursued further in this study.

In summary, the CBN warm pool develops in the late summer and fall primarily due to increasing solar radiation, helped by reduced evaporation in the early warming stage. The coastal upwelling off the South American continent and horizontal advection of the cold water by the Caribbean Current significantly reduces the warming rate of the $\mathrm{CBN}$ during the summer. The reduced shortwave radiation at the surface, aided by intensifying trade winds in the winter and thus increased evaporation, is mainly responsible for the decay of the CBN warm pool in OND.

\section{Impact of variable mixed layer depth}

One shortcoming of using the $z$ coordinate in the HYCOM simulation is that mixed layer depth is not a prognostic variable; thus a heavy interpolation is usually required to diagnose the mixed layer depth and associated mixed layer heat budget terms. Because of large interpolation errors, we can only use a slab heat budget analysis with an assumption that the temporal and spatial variations in mixed layer depth are not significant. As discussed in the previous section, this assumption tends to break down in boreal winter when the mixed layer depth is usually much deeper, and this causes some problems in our heat budget analyses especially over the Atlantic-side warm pool during its de- cay phase. In an effort to overcome the restriction of slab heat budget analysis, we carry out another HYCOM experiment by configuring the model using a purely isopycnal-coordinate system. As in the Miami Isopycnal Coordinate Ocean Model (MICOM) version 2.8 , the surface mixed layer is modeled by a bulk mixed layer and the turbulent mixing across the base of mixed layer is explicitly computed using the turbulence energy budget equation of Gaspar (1988). Below the bulk mixed layer, 15 layers of uniform potential densities are used, and the density anomalies for the 15 isopycnal layers are $24.00,24.70,25.28,25.77,26.18,26.52,26.80$, $27.03,27.22,27.38,27.52,27.64,27.74,27.82,27.88$, and 27.94 in the $\sigma_{\theta}$ unit. The model domain, horizontal grid resolution, surface forcing, and initialization are all the same as the z-coordinate HYCOM simulation. For convenience, this model configuration is referred to as a MICOM mode hereafter because it is virtually identical to the MICOM version 2.8 (Bleck et al. 1992). Like other isopycnal-coordinate ocean models (e.g., Oberhuber 1993), the MICOM mode contains many noble features, such as the explicit treatments of mixed layer depth and turbulent flux across the mixed layer base, which are favored by many theoreticians. However, there are some critical problems in applying the output of MICOM mode simulation for a mixed layer heat budget analysis, and thus they are briefly discussed here.

In spring, the depth of surface mixed layer usually exceeds the Monin-Obukov length; thus the mixed layer water detrains and forms a new isopycnal layer. In the MICOM mode simulation, this newly formed isopycnal layer must be allocated to one of the existing isopycnal layers, and the isopycnal layer that receives the detrained water is always denser than the detrained water. Because diabatic heat changes in interior isopycnal layers are strictly prohibited in the MICOM mode, the diabatic heat associated with detrainment must be returned to the mixed layer to conserve the total heat, thus resulting in an artificial increase in the mixed layer temperature.

The mixed layer detrainment algorithm adopted in the MICOM mode is the strategy developed by Bleck et al. (1992). This so-called buffered detrainment algorithm is designed to minimize the detrainment-induced warming of the mixed layer water by mixing a portion of the detrained water with the receiving isopycnal layer while returning the remaining portion back to the mixed layer. Our MICOM mode simulation using this strategy is not successful because the rate of detrainment-induced heating is as large as $20 \mathrm{~W} \mathrm{~m}^{-2}$, which is larger than the heat flux across the warm pool base in 
boreal spring, thus contaminating the warm pool heat budget during the onset phase. In an effort to suppress this numerical error in the mixed layer heat budget, we use an ad hoc strategy that can be particularly useful in the tropical oceans. The basic idea underlying this scheme is to discharge extra salt from the mixed layer to the detrained water in order to make the detrained water heavy enough so that it can be mixed with the receiving isopycnal layer. This scheme allows the mixed layer to fully recede to the Monin-Obkov length in spring and the detrainment-induced diabatic heat to remain in the receiving isopycnal layer; thus detrainment does not cause diabatic heat change in the mixed layer. Some side effects are observed, such as a freshening of the mixed layer, a drift in $T-S$ property of the receiving layers and increasing of the mixed layer stability, but they do not seem to cause a major problem over the WHWP region.

Other limitations of the MICOM mode relevant to this study involve the parameterizations of shortwave radiation and shear-driven turbulent mixing. These two processes are simply ignored in the MICOM mode simulation, and this may cause problems particularly for the ENP warm pool because penetrative shortwave heat flux, and shear-driven turbulent mixing are important cooling mechanisms there (Fig. 2, second panel). The upshot is that we must be cautious about interpreting the output of the MICOM mode simulation because of the limitations discussed here. Therefore, we use the MICOM mode simulation only to assess the impact of mixed layer depth variations on the WHWP heat budget. And we are particularly interested in the winter

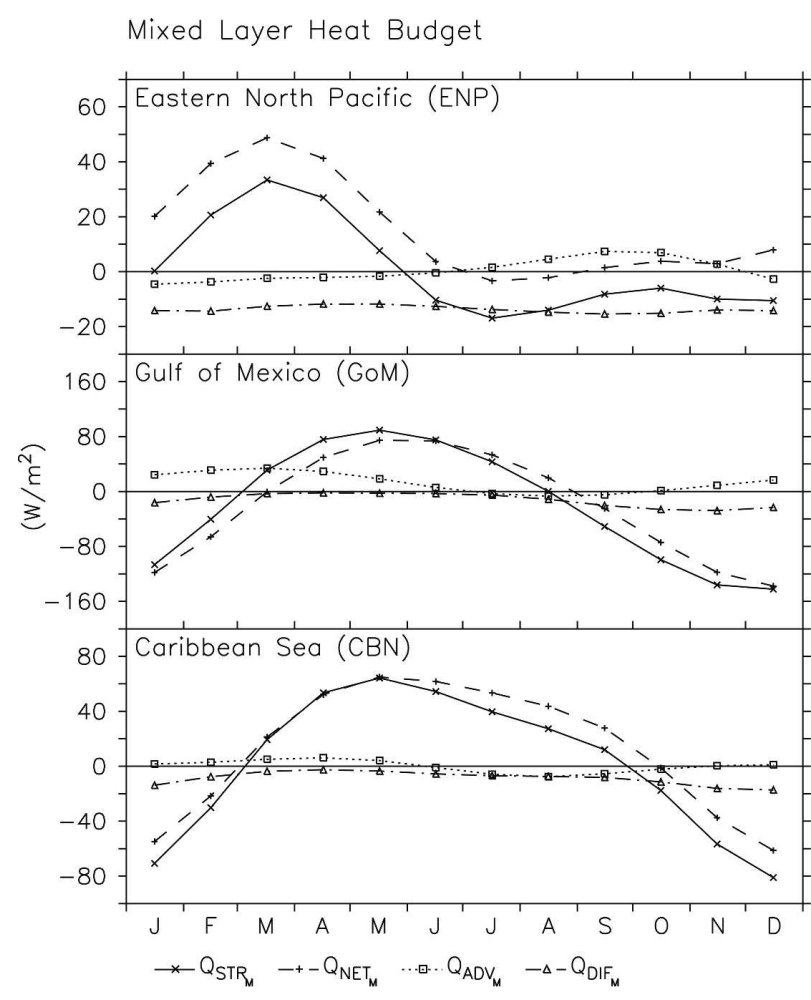

FIG. 7. The seasonal cycle of the area-averaged mixed layer heat budgets for the (top) ENP, (middle) GoM, and (bottom) CBN regions, derived from the MICOM mode simulation.

mixed layer heat budgets over the Atlantic warm pool regions, the GoM and CBN.

The heat budget equation that governs the diabatic heating rate in the bulk mixed layer can be written as

$$
\underbrace{\rho c_{p} h_{M} \frac{\partial T_{M}}{\partial t}}_{Q_{\mathrm{STR}_{M}}}=\underbrace{R l_{0}+Q_{\mathrm{LAT}_{M}}+Q_{\mathrm{SEN}_{M}}}_{Q_{\mathrm{NET}_{M}}} \underbrace{-\rho c_{p} \mathbf{v}_{M} \cdot \nabla T_{M}}_{Q_{\mathrm{ADV}_{M}}} \underbrace{-w_{e}\left(T_{M}-T_{e}\right)}_{Q_{\mathrm{DIF}_{M}}},
$$

where $h_{M}, T_{M}$, and $\mathbf{v}_{M}$ are the depth, temperature, and velocity vector of bulk mixed layer, respectively; $w_{e}$ is the entrainment rate; and $T_{e}$ is the temperature of an isopycnal layer being entrained. The lhs is the heat storage rate $\left(Q_{\mathrm{STR}_{M}}\right)$, and the rhs includes the surface net heat flux $\left(Q_{\mathrm{NET}_{M}}\right)$, the advective heat flux divergence $\left(Q_{\mathrm{ADV}_{M}}\right)$, and the turbulent heat flux (or entrainment cooling) across the mixed layer base $\left(Q_{\mathrm{DIF}_{M}}\right)$, respectively. Note that the subscript $M$ is used to distinguish the mixed layer heat budget terms from those of the slab heat budget. The advective heat flux divergence term $\left(Q_{\mathrm{ADV}_{M}}\right)$ contains only the horizontal component because the vertical component does not explicitly contribute to diabatic heating. For convenience, heating associated with winter convection is partitioned to the turbulent heat flux term $\left(Q_{\mathrm{DIF}_{M}}\right)$ as in the slab heat budget. Penetrative shortwave heat flux is always zero in the MICOM mode simulation as pointed out earlier, and thus it is missing in (8). The horizontal subgrid diffusion term is ignored because it is small.

The top panel in Fig. 7 shows the simulated seasonal cycles of mixed layer heat budget terms averaged over the ENP region, and it clearly shows that the vertical mixing $\left(Q_{\mathrm{DIF}_{M}}\right)$ is a persistent yearlong cooling term. This result is consistent with the slab heat budget because the diffusive heat flux $\left(Q_{\mathrm{DIF}}\right)$ in the slab heat budget is also a cooling term that persists yearlong (Fig. 2 , second panel). The advective heat flux divergence 


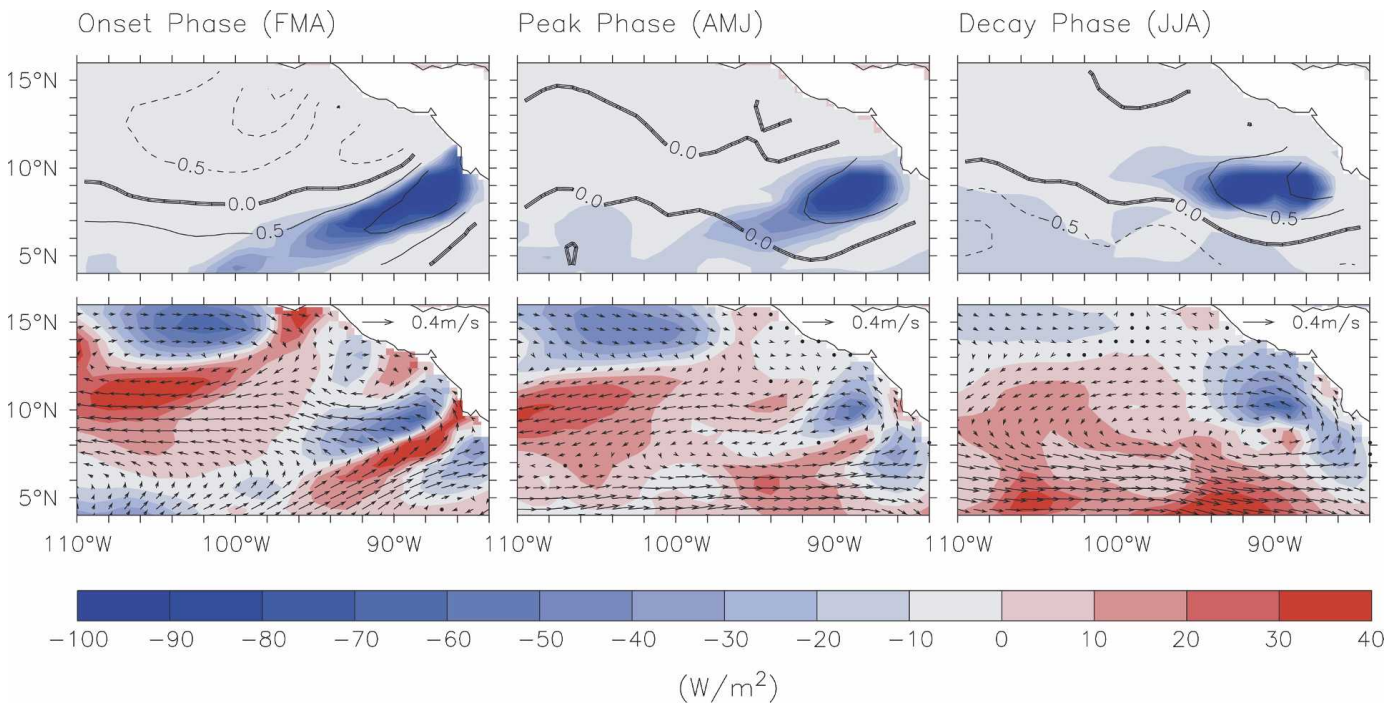

FIG. 8. (top) The rate of entrainment cooling (colored) and wind stress curl $\left(10^{7} \mathrm{Nm}^{-3}\right.$; contoured) for the CBN slab. (bottom) The rate of advective heat flux divergence ( $\mathrm{W} \mathrm{m}^{-2}$; colored) and the velocity vector of the mixed layer. All values are derived from the MICOM mode simulation. (left) The onset phase (JJA), (middle) the peak phase (ASO), and (right) the decay phase (OND).

$\left(Q_{\mathrm{ADV}_{M}}\right)$ remains small during all three phases of the ENP warm pool, and this result is also consistent with the slab heat budget because the horizontal component of the advective heat flux divergence is very small in the slab heat budget.

The vertical advective heat flux divergence in the slab heat budget (1) is not explicitly represented by any separable term in the mixed layer heat budget (8) because it does not explicitly contribute to diabatic heating. Although upwelling does not change the mixed layer temperature directly, it brings the isotherms and cold subsurface water closer to the surface where turbulent mixing is greater, thus increasing the rate of entrainment cooling in the mixed layer. The upper panels of Fig. 8 clearly show the signature of Ekman-induced upwelling that increases the entrainment cooling $\left(Q_{\mathrm{DIF}_{M}}\right)$ over the Costa Rica Dome. The temporal and spatial distributions of $Q_{\mathrm{DIF}_{M}}$ are, thus, very similar to those of the vertical advective heat flux divergence in the slab heat budget (Fig. 3, top). The advective heat flux divergence $\left(Q_{\mathrm{ADV}_{M}}\right)$ and the mixed layer velocity vector (lower panels of Fig. 8) indicate that the cold water entrained from the subsurface is advected northwesterward into the Gulfs of Tehuantepac and Papagayo, again consistent with the slab heat budget (Fig. 3, bottom).

In the GoM region (Fig. 7, middle), the mixed layer heat budget looks quite different from the slab heat budget in winter season. The most striking difference is between the two turbulent mixing terms, $Q_{\mathrm{DIF}_{M}}$ and $Q_{\mathrm{DIF}}$. In the slab heat budget, $Q_{\mathrm{DIF}}$ is a strong warming term in winter as a result of intense cooling at the sea surface and subsequent convective motion that warms up the surface water. In the mixed layer heat budget, on the other hand, $Q_{\mathrm{DIF}_{M}}$ is a cooling term because the convective warming is much weakened at the base of deep winter mixed layer but the entrainment cooling is more intense there (due to the large temperature jump). Another interesting point is that the advective heat flux divergence $\left(Q_{\mathrm{ADV}_{M}}\right)$ is quite large and positive in spring months (FMA). This is because the mixed layer is much colder in the GoM than in the CBN region during FMA $\left(\Delta T \sim 2.8^{\circ} \mathrm{C}\right)$; thus the surface western boundary current that is approaching from the Caribbean warms up the mixed layer water in the GoM. The advective heat flux divergence, however, decays rapidly as the Gulf water warms up in early summer, and thus it plays only a minor role during the onset phase of the GoM warm pool.

In the CBN, turbulent mixing $\left(Q_{\mathrm{DIF}_{M}}\right)$ is a cooling term in winter as in the GoM, suggesting that entrainment cooling contributes to the demise of the CBN warm pool. The advective heat flux divergence $\left(Q_{\mathrm{ADV}_{M}}\right)$ and turbulent mixing $\left(Q_{\mathrm{DIF}_{M}}\right)$ during the onset and peak phases are much smaller in the mixed layer heat budget in comparison to those in the slab heat budget. However, we find that the magnitude of turbulent mixing $\left(Q_{\mathrm{DIF}_{M}}\right)$ is quite sensitive to the choice of detrainment algorithm used in the MICOM mode simulation; thus, we interpret the mixed layer heat budget only qualitatively. Although not shown here, the turbulent mixing $\left(Q_{\mathrm{DIF}_{M}}\right)$ is strong over the coastal up- 
TABLE 1. The model-generated values of diffusive and advective heat flux for the peak phases of the ENP, GoM, and CBN regions are compared with those obtained in EL05. In the case of EL05, two values of advective heat flux divergence are shown: those in the left are obtained indirectly using the bubble equation, and those in the right (parentheses) are obtained using the surface drifter data. All values are derived using the $27^{\circ} \mathrm{C}$ isotherm as the isothermal boundary for the bubble heat budget analysis.

\begin{tabular}{lccrccr}
\hline \hline & \multicolumn{2}{c}{$Q_{\mathrm{DIF}_{B}}\left(\mathrm{~W} \mathrm{~m}^{-2}\right)$} & & \multicolumn{2}{c}{$Q_{\mathrm{ADV}}\left(\mathrm{W} \mathrm{m}^{-2}\right)$} \\
\cline { 2 - 3 } \cline { 5 - 6 } Region & EL05 & HYCOM & & EL05 & HYCOM \\
\hline ENP & -20.2 & -24.9 & & $-2.9(-2.0)$ & -10.2 \\
GoM & -13.4 & -24.5 & & $-14.4(-5.5)$ & -8.6 \\
CBN & -9.7 & -18.7 & & -8.1 & -15.2 \\
\hline
\end{tabular}

welling off the South American continent due to predominant easterlies and positive wind curl in the southern Caribbean. The temporal and spatial distributions of $Q_{\mathrm{DIF}_{M}}$ are, thus, very similar to those of the vertical advective heat flux divergence $\left(Q_{\mathrm{DIF}}\right)$ in the slab heat budget (Fig. 6, upper panels).

In summary, we find that the mixed layer heat budget is quite consistent with the slab heat budget in the ENP warm pool in such a way that Ekman-induced year-long cooling over the Costa Rica Dome is represented by the vertical advective heat flux divergence $\left(Q_{\mathrm{ADV}}\right)$ and turbulent cooling term $\left(Q_{\mathrm{DIF}_{M}}\right)$ in the slab and mixed layer heat budget, respectively. Over the Atlantic side, we find that intense entrainment cooling across the deep winter mixed layer is an important player in the demise of Atlantic warm pool.

\section{Comparison with EL05}

In an effort to validate our slab heat budget analysis, the model-generated values of diffusive and advective heat flux for the peak phases are compared to those obtained in EL05. To be consistent with EL05, the diffusive heat flux is recomputed by applying the so-called "bubble heat budget equation" to the model output, and it is referred to as $Q_{\mathrm{DIF}_{B}}$ to distinguish it from the diffusive heat flux $\left(Q_{\mathrm{DIF}}\right)$ in the slab heat budget (1). The bubble heat budget equation used in EL05 describes the heat balance within a three-dimensional ocean volume bounded by the sea surface and an oceanic isothermal surface. With heat advection across the isothermal boundary canceled out, the total (horizontal plus vertical) diffusive heat flux across the isothermal boundary is estimated as a residual in the bubble equation. EL05 subsequently used a slab heat budget to estimate total advective heat flux divergence, but they were unable to separate the horizontal and vertical components of $Q_{\mathrm{ADV}}$.

Table 1 shows the model-generated values of diffu- sive heat flux $\left(Q_{\mathrm{DIF}_{B}}\right)$ and advective heat flux divergence $\left(Q_{\mathrm{ADV}}\right)$ for the peak phase of each WHWP subregion along with those from EL05. In the case of EL05, two values of advective heat flux divergence are shown: those in the left are obtained indirectly using the bubble equation, and those in the right (parentheses) are obtained using the surface drifter data. All values are obtained using the $27^{\circ} \mathrm{C}$ isotherm as the isothermal boundary for the bubble heat budget analysis. In general, the model estimates agree with EL05 in that both $Q_{\mathrm{DIF}_{B}}$ and $Q_{\mathrm{ADV}}$ are cooling terms in all three WHWP regions. The maximum diffusive cooling occurs in the ENP region in both EL05 and the HYCOM simulation, and the two estimates are in good agreement. Somewhat larger differences between the EL05 and HYCOM simulation are also noted, and they are caused by the bias in surface heat flux data, the sparseness of surface drifter data, and possibly the bias in the HYCOM simulation. Overall, the model simulation confirms the EL05 estimates of $Q_{\mathrm{DIF}_{B}}$ and $Q_{\mathrm{ADV}}$ within the range of $4.7 \sim 11.1 \mathrm{~W} \mathrm{~m}^{-2}$.

\section{Summary and discussions}

This study takes an alternate approach to that of EL05 for estimating the warm pool heat budget. EL05 dealt only with observations and the heat budget integrated over conterminous warm pool regions to estimate total diffusive heat flux across a bounding isotherm as a residual; they then used a slab approach in each subregion to derive the total advective heat flux divergence as a residual by treating the diffusive flux as a known input. However, because the diffusive flux can only be estimated for the peak warm pool season when the warm pool can be defined by a reasonable isotherm, only peak season estimates of the heat budget could be made. By using a HYCOM model simulation of the warm pool optimized against observations (LEW05), we have been able to estimate all terms of the heat budget explicitly as functions of time and space, by integrating them over the subregional slabs. The analysis gives much more detailed heat budgets by region, and in most instances it confirms the EL05 estimates of diffusion and advective heat flux divergence for the peak seasons within acceptable limits.

The main conclusion of this study is that the WHWP cannot be considered as a monolithic whole with a single set of dominating processes that explain its behavior, consistent with previous studies. The three regions considered are each unique in terms of the atmospheric and/or oceanic processes that dominate the corresponding heat budgets. In all cases some combination of surface fluxes is important, but mainly clear-sky ra- 
diation, cloud radiative forcing, and evaporation. In the ENP region cloud cover plays a crucial role by modifying the impact of clear-sky radiation, and ocean upwelling in the Costa Rica Dome connected to surrounding areas by horizontal advection offers a persistent yearlong cooling mechanism. The Caribbean is affected by upwelling and horizontal advection within and away from the coastal upwelling zone off northern South America during the onset and peak phases, thus slowing down the development of the warm pool. And advective processes are of less importance in the GoM region. Common to all three WHWP regions is the reduction of wind speed in the peak phase, suggestive of a convection-evaporation feedback known to be important in the Indo-Pacific warm pool dynamics (Zhang et al. 1995). During the peak phase, the air-sea temperature (humidity) gradient is maximized, but the latent heat flux (moisture flux) is less effective because of the reduced wind speed. During the decay phase, the wind speed increases again and thus the latent heat flux increases, providing an important cooling mechanism for the WHWP.

In summary, the seasonal onset and decay of the WHWP can be described as follows. Increased clearsky shortwave radiation flux in boreal spring is mainly responsible for the appearance of the WHWP in the ENP region around March. The clear-sky radiation remains strong until September, but the increased cloudiness associated with the Pacific ITCZ approaching from the south blocks much of the clear-sky shortwave radiation flux in boreal summer (May-October). The shielding effect of deep convective clouds is aided by the convection-evaporation feedback, and thus the associated increase in evaporation appears to be the major factor in cooling off the WHWP in the ENP region, eventually prompting a migration of the WHWP into the Atlantic Ocean around June. Over the Atlantic, the clear-sky radiation flux that increases monotonically from December to May and decreases later is largely responsible for the onset and decay of the Atlantic warm pool in boreal summer while other fluxes modulate the heating rate slightly. The coastal upwelling along the northern coast of South America and horizontal advection of the cold water by the Caribbean Current significantly reduces the warming rate over the $\mathrm{CBN}$ region during the onset and peak phases (JuneOctober). The convection-evaporation feedback and the associated increase in evaporation plays an important role in the demise of the WHWP over the GoM and CBN regions in late summer. Further analysis suggests that entrainment cooling across the deep winter mixed layer also contributes to the demise of Atlantic warm pool.
This study demonstrates that an OGCM simulation is a useful tool for quantifying and understanding the thermodynamics of the warm pool more completely and effectively than is possible using only observational data. However, there are also some shortcomings in our OGCM simulation that need to be improved in the future. In particular, the slab heat budget analysis, which is used as the main tool in this study, tends to be inappropriate over the Atlantic warm pool regions in boreal winter when the mixed layer undergoes a rapid deepening. To account for variable mixed layer depth, a supplementary model simulation is performed by reconfiguring HYCOM with a purely isopycnalcoordinate system (MICOM mode simulation). Although the mixed layer heat budget equation contains terms that are different from those in the slab heat budget equation, the two heat budgets are physically consistent in the ENP region. In the Atlantic warm pool regions, we find that the slab heat budget analysis is misleading in the winter season. However, the MICOM mode simulation also has some problems of its own. The most critical problem is the detrainment algorithm (Bleck et al. 1992) that causes an artificial warming of the mixed layer. An ad hoc scheme is used to suppress this numerical problem, and this scheme seems to work reasonably well over the WHWP region, but we need a more comprehensive and physically sound scheme that works for all part of the global ocean.

Another shortcoming in our OGCM simulation is the horizontal model resolution. In particular, a highresolution model simulation is required to better assess the impact of the regional western boundary current system in the GoM region (i.e., Yucatan Current, Loop Current, and Florida Current). Similarly, the highresolution simulation will be also useful to explore the influence of the warm North Brazil Current Rings entering into the $\mathrm{CBN}$ basin. In future work, direct estimates of advective fluxes from available observational data combined with the high-resolution model simulation will be used to validate the model results discussed here.

Acknowledgments. We thank George Halliwell and Rainer Bleck for their help on implementing the heat budget computation routine in HYCOM and revising the detrainment algorithm in MICOM. We also want to thank two anonymous reviewers, Sumant Nigam, Rick Lumpkin, Alberto Mestas-Nuez, and Libby Johns for reviewing the manuscript. This research is supported by the NOAA PACS and CPPA. The findings and conclusions in this report are those of the authors and do not necessarily represent the views of the funding agency. 


\section{REFERENCES}

Bleck, R., 2002: An oceanic general circulation model framed in hybrid isopycnic-Cartesian coordinates. Ocean Modell., 4, $55-88$.

, C. Rooth, D. Hu, and L. T. Smith, 1992: Salinity-driven thermocline transients in a wind- and thermohaline-forced isopycnic coordinate model of the North Atlantic. J. Phys. Oceanogr., 22, 1486-1505.

Bosilovich, M. G., 2002: On the vertical distribution of local and remote sources of water for precipitation. Meteor. Atmos. Phys., 80, 31-41.

Chelton, D. B., M. H. Freilich, and S. K. Esbensen, 2000: Satellite observations of the wind jets off the Pacific coast of Central America. Part II: Regional relationships and dynamical considerations. Mon. Wea. Rev., 128, 2019-2043.

Conkright, M. E., and Coauthors, 2002: World Ocean Database 2001. National Oceanographic Data Center, CD-ROM.

Enfield, D. B., and S.-K. Lee, 2005: The heat balance of the Western Hemisphere warm pool. J. Climate, 18, 2662-2681.

Gaspar, P., 1988: Modeling the seasonal cycle of the upper ocean. J. Phys. Oceanogr., 18, 161-180.

Grist, J. P., and S. A. Josey, 2003: Inverse analysis adjustment of the SOC air-sea flux climatology using ocean heat transport constraints. J. Climate, 16, 3274-3295.

Hofmann, E. E., A. J. Busalacchi, and J. J. O’Brien, 1981: Wind generation of the Costa Rica Dome. Science, 214, 552-554.

Kalnay, E., and Coauthors, 1996: The NCEP/NCAR 40-Year Reanalysis Project. Bull. Amer. Meteor. Soc., 77, 437-471.

Large, W. G., J. C. McWilliams, and S. C. Doney, 1994: Oceanic vertical mixing: A review and a model with a non-local boundary layer parameterization. Rev. Geophys., 32, 363403.

Lee, S.-K., D. B. Enfield, and C. Wang, 2005: Ocean general circulation model sensitivity experiments on the annual cycle of Western Hemisphere Warm Pool. J. Geophys. Res., 110, C09004, doi:10.1029/2004JC002640.

Levitus, S., and T. P. Boyer, 1994: Temperature. Vol. 4, World Ocean Atlas 1994, NOAA Atlas NESDIS 4, 117 pp.

— , R. Burgett, and T. P. Boyer, 1994: Salinity. Vol. 3, World Ocean Atlas 1994, NOAA Atlas NESDIS 3, 99 pp.
McCreary, J. P., H. S. Lee, and D. B. Enfield, 1989: The response of the coastal ocean to strong offshore winds: With application to circulations in the Gulfs of Tehuantepec and Papagayo. J. Mar. Res., 47, 81-109.

McGregor, G. R., and S. Nieuwolt, 1998: Tropical Climatology: An Introduction to the Climates of the Low Latitudes. $2 \mathrm{~d}$ ed. John Wiley \& Sons, 339 pp.

Niiler, P. P., and J. Stevenson, 1982: On the heat budget of tropical warm water pools. J. Mar. Res., 40 (Suppl.), 465-480.

Oberhuber, J. M., 1993: Simulation of the Atlantic circulation with a coupled sea ice-mixed layer-isopycnal general circulation model. Part I: Model description. J. Phys. Oceanogr., 23, 808-829.

Ramanathan, V., B. Subasilar, G. J. Zhang, W. Conant, R. D. Cess, J. T. Kiehl, H. Grassl, and L. Shi, 1995: Warm pool heat budget and shortwave cloud forcing: A missing physics? Science, 267, 499-503.

Raymond, D. J., and Coauthors, 2004: EPIC2001 and the coupled ocean-atmosphere system of the tropical east Pacific. Bull. Amer. Meteor. Soc., 85, 1341-1354.

Schneider, N., T. Barnett, M. Latif, and T. Stockdale, 1996: Warm pool physics in a coupled GCM. J. Climate, 9, 219-239.

Wang, C., and D. B. Enfield, 2001: The tropical Western Hemisphere warm pool. Geophys. Res. Lett., 28, 1635-1638.

_ , and _ 2003: A further study of the tropical Western Hemisphere warm pool. J. Climate, 16, 1476-1493.

, S.-K. Lee, and C. W. Landsea, 2006: Influences of the Atlantic warm pool on Western Hemisphere summer rainfall and Atlantic hurricanes. J. Climate, 19, 3011-3028.

Xie, S.-P., H. Xu, W. S. Kessler, and M. Nonaka, 2005: Air-sea interaction over the eastern Pacific warm pool: Gap winds, thermocline dome, and atmospheric convection. J. Climate, 18, 5-20.

Zhang, G. J., and M. J. McPhaden, 1995: The relationship between sea surface temperature and latent heat flux in the equatorial Pacific. J. Climate, 8, 589-605.

—, V. Ramanathan, and M. J. McPhaden, 1995: Convectionevaporation feedback in the equatorial Pacific. J. Climate, 8, 3040-3051. 